NEWS

\title{
EU science fund targets young guns
}

\section{MUNICH}

Ten years ago, few would have imagined a European Union-wide fund for basic research, distributed without restrictions on scientific creed or country. The idea that the notoriously bureaucratic European Commission would finance such a fund, with no strings attached, would have stretched credibility too far.

But two decisions last week moved the much-heralded European Research Council (ERC) closer to reality.

The European Council of Ministers has approved a budget of $€ 7.5$ billion (US $\$ 9.7$ billion) over seven years. And the fledgling ERC's scientific council has agreed on a first funding stream, open to any scientist embarking on an independent research career.

Soon after that, a second stream of funding will be opened to investigators in all disciplines. Individual investigators may apply for grants of up to $€ 1$ million, and there is just one criterion for selection: excellence in cuttingedge research.

${ }^{\alpha}$ ERC grants will be like the National Institutes of Health's R01 investigator grants," says Fotis Kafatos, a biologist at Imperial College London and chairman of the ERC's scientific council. "Individuals can put in an application at any time."

European scientists are famously frustrated by the complicated requirements of European Union (EU) Framework research programmes. These generally require multidisciplinary, multinational research groups working towards a defined industrial or social goal. Many have advocated an ERC for decades, arguing that it would raise the quality of research and provide a new source of funding for scientists in countries where national funds are paltry.

The question was always: who would pay? National research agencies have legal and psychological difficulties with putting part of their funds into an international pot. And the European Commission has no mandate to fund basic research, its aim being to promote industrial competitiveness and improve quality of life in Europe.

Mounting pressure from scientists eventually prompted a pragmatic solution, and the ERC is now part of the EU's next Framework Programme, FP7, which will run from 2007 to 2013.

On 30 May, the council of ministers approved a budget of $€ 50.5$ billion for that programme and agreed on how it would be broken down, including the ERC's share. The plan must be ratified on 15 June by the European parliament, but is expected to pass with no major changes.

\section{Foot on the ladder}

The ERC's funding is less than had been hoped for when the concept began to gain momentum in 2002. "But it is not crumbs," says Kafatos. The annual budget will start at $€ 300$ million, rising to $€ 1.5$ billion in the seventh and last year. By then, Kafatos hopes, the ERC will have proved its value to politicians, and future Framework programmes would receive at least that much money.

In the meantime, the ERC will open its
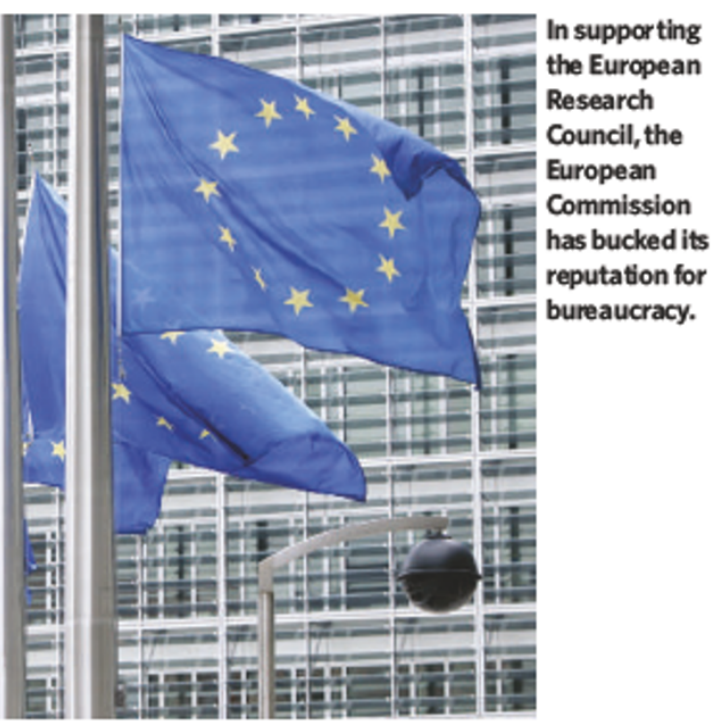

Starting Grant scheme in its first year, aimed at scientists who are within ten years of completing their $\mathrm{PhDs}$ and seeking their first post as an independent investigator.

"There are many countries where young scientists are kept dependent for far too long on their professors," says Kafatos. "This programme will allow them independence earlier."

Julia Fischer, an animal-behaviour specialist at the German Primate Centre in Göttingen, agrees. "There is a big difference between countries," she says. "In the United Kingdom it is easier to get on the career ladder than in Germany, for example. Fischer is on the board of the Young Academy, which comprises 50 top young scientists in German-speaking countries.

One of the biggest concerns facing the ERC is the danger of oversubscription. There are well over a million full-time

"We have no idea how many scientists across the EU would in fact be eligible for the starting-investigators programme, or how many will apply, admits Helga Nowotny, a social scientist at the Vienna Centre for Urban Knowledge Management and vice-chair of the ERC's scientific council.

But, she says, the planned two-stage selection process will ease the pain of any oversubscription. In the first stage, applicants must summarize their projects and give information about the research team that would carry them out. The winners in this round will be invited within six weeks to submit a full application.

The council will establish at least 15 panels, organized by subject, to handle the final decisions. The panels will choose external referees to review the full proposals. This differs from the selection procedures of the Framework programmes, where the commission selects evaluators from a list of scientists who have volunteered for the job. "That is not a good system," says Nowotny.

The scientific council is now consulting organizations such as national granting agencies and academies to identify panel members. "Only those with strong scientific reputations will be selected to join panels," says Kafatos.

He doesn't think oversubscription will be a problem. "Scientists will exercise self-evaluation," he says. "Knowing that only frontier research is going to be funded, only those who have really excellent proposals will apply." ․ Alison Abbott 